\title{
Role of Topical Nitroglycerin in Preventing Keystone Flap Necrosis
}

\author{
K Sri Harsha Reddy ${ }^{1}$, Ravi Kumar Chittoria*, ${ }^{*}$, Nishad K ${ }^{1}$, Neljo Thomas ${ }^{1}$, R. Srinath ${ }^{3}$, Indushekar TC ${ }^{3}$, Sriram VS ${ }^{3}$ \\ ${ }^{1}$ Senior Resident, Department of Plastic Surgery, JIPMER, Pondicherry, India \\ ${ }^{2}$ Professor \& Registrar (Academic), Head of IT Wing and Telemedicine, Department of Plastic Surgery \& Telemedicine, JIPMER, \\ Pondicherry, India \\ ${ }^{3}$ Junior Resident, Department of Surgery, Jawaharlal Institute of Postgraduate Medical Education and Research Institute (JIPMER), \\ Puducherry, India
}

*Corresponding author: Ravi Kumar Chittoria, Professor \& Registrar (Academic), Head of IT Wing and Telemedicine, Department of Plastic Surgery \& Telemedicine, JIPMER, Pondicherry, India

Received date: 07 February, 2022 $\quad$ Accepted date: 21 February, 2022 | Published date: 24 February, 2022

Citation: Reddy KSH, Chittoria RK, Nishad K, Thomas N, Srinath R, et al. (2022) Role of Topical Nitroglycerin in Preventing Keystone Flap Necrosis. J Orthop Pract 2(1): doi https://doi.org/10.54289/JOP2200101

Copyright: (C) 2022 Reddy KSH, et al. This is an open-access article distributed under the terms of the Creative Commons Attribution License, which permits unrestricted use, distribution, and reproduction in any medium, provided the original author and source are credited.

\begin{abstract}
In plastic and reconstructive surgery, skin flaps are widely employed. Large wounds that cannot be closed with normal treatments are treated with skin flap surgery. Skin flap necrosis is a well-known post-flap cover issue that can affect cosmetic outcomes and patient satisfaction. Variable occurrence rates and inconsistent related factors have been reported in many retrospective studies of this condition. Despite advances in technology, the rate of flap necrosis remains significant in daily procedures. Topical Nitroglycerin (NTG) has shown potential in decreasing flap necrosis in several randomized trials. In this case study, we aim to evaluate the efficacy and safety of topical NTG in preventing flap failure.
\end{abstract}

Keywords: Keystone flap failure, Necrosis, Topical Nitroglycerin.

\section{Introduction}

Skin flap necrosis is a well-known post-flap cover issue that can affect cosmetic outcomes and patient satisfaction. Variable occurrence rates and inconsistent related factors have been reported in many retrospective studies of this condition. Despite advances in technology, the rate of flap necrosis remains significant in daily procedures. Nitroglycerin relaxes vascular smooth muscle by acting as a vasodilator by producing nitric oxide [1]. Another wellknown benefit is that it has anti-thrombotic effects. Increased blood flow to the application region is achieved by increasing the caliber of the vasculature and ensuring its patency [2]. Topical Nitroglycerin (NTG) has shown potential in decreasing flap necrosis in several randomized trials. In this case study, we aim to evaluate the efficacy and safety of topical NTG in preventing flap failure.

\section{Materials and Methods}

This study was conducted in the Department of Plastic surgery in a Tertiary care centre in South India. Departmental ethical clearance and consent from the subject were obtained. In this study, we have applied topical nitroglycerin (solution 
form) to a 20-year-old patient (no known comorbidities) who has undergone a keystone flap to provide cover for an exposed bony surface over the right lower limb. The flap was then monitored for signs of failure on days 5,10,15 (figure $1,2,3)$.

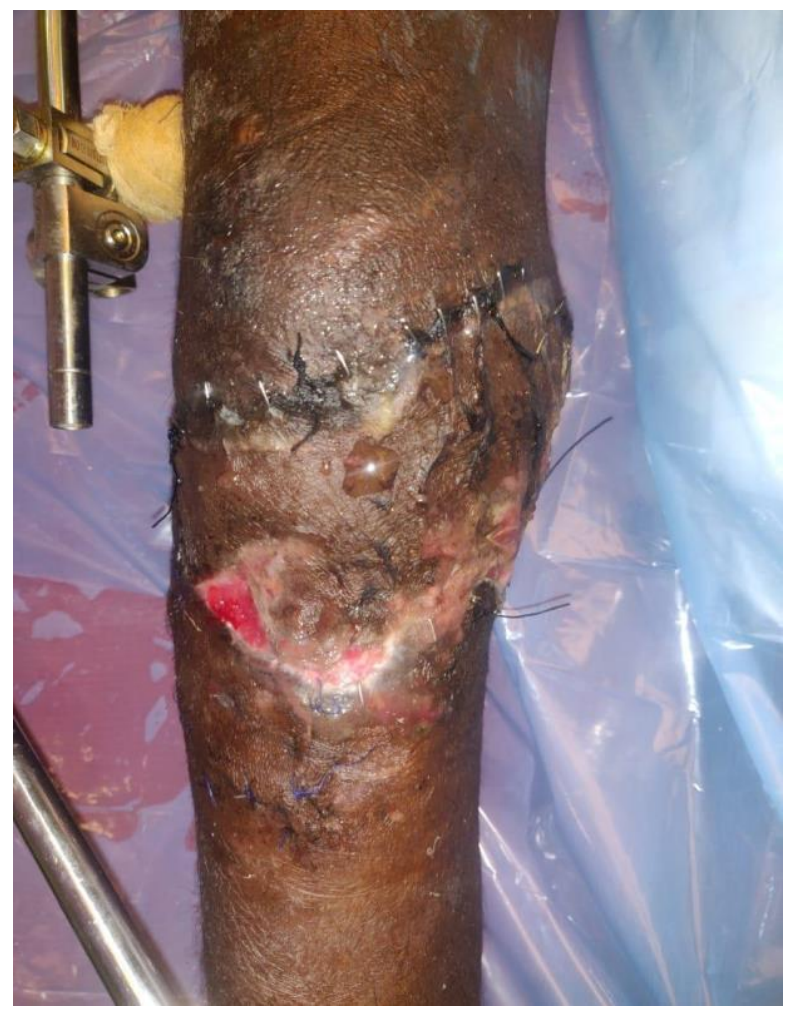

Figure 1: Flap on Day 5

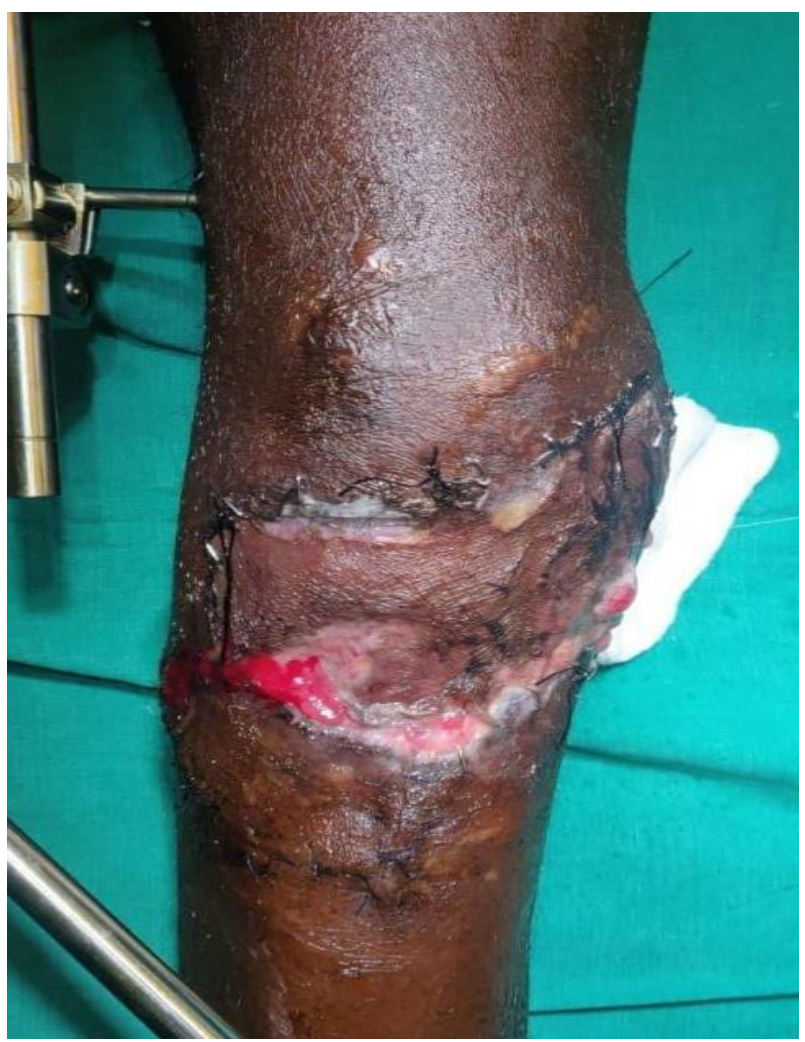

Figure 2: Flap on Day 10 


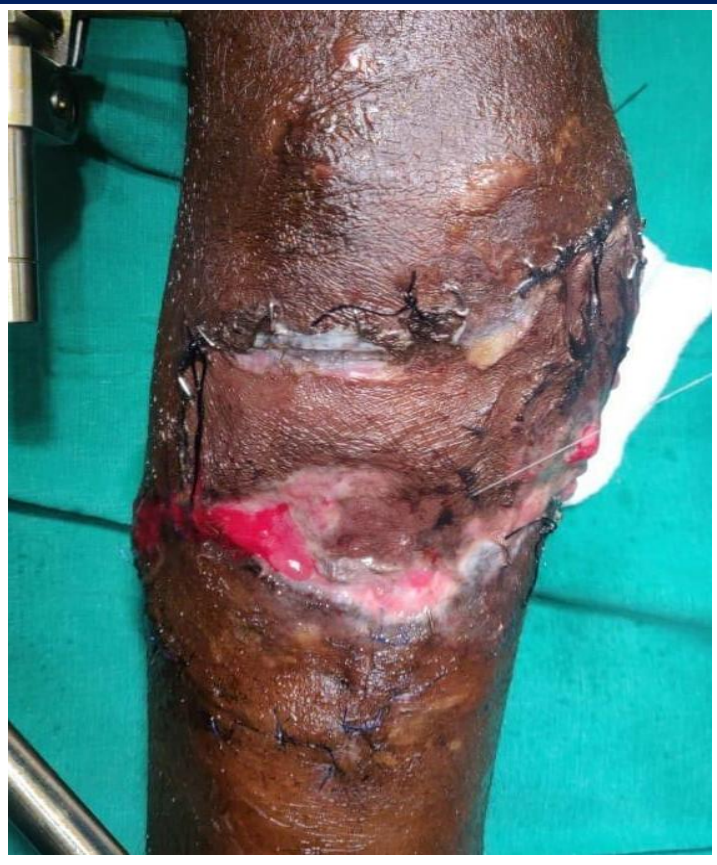

Figure 3: Flap on day 15

\section{Result}

In our study, topical NTG application was successful in preventing skin flap necrosis of the keystone flap. The viability of the flap was checked by the skin colour and the flap blood sugar/normal blood sugar ratio (> 0.6).

\section{Discussion}

In plastic and reconstructive surgery, skin flaps are widely employed. Large wounds that cannot be closed with normal treatments are treated with skin flap surgery. Keystone flaps are one of the preferred options to reconstruct different types of defects, especially in the extremities. The keystone flap is different from other loco-regional flaps in that it has a great capability for adaptability. The various factors that could contribute to skin flap necrosis are age, BMI, tobacco, smoking, Diabetes, wound type and size, etc. In our patient, none of these risk factors were present hence the effect of NTG on preventing flap necrosis could be evaluated more efficiently.

A well-perfused, healthy flap will be pink, enlarged minimally in the postoperative period, and warm to the touch. Capillary refill is measured by pressing and releasing pressure on a skin paddle with a fingertip, then noting the initial pallor from direct pressure, followed by the restoration of a pink hue from reperfusion. A bluish tint, increased swelling and warmth, and a shorter capillary refill (less than 2 seconds) are all signs of a congested (venous compromised) flap. The flap will be pale in colour, cold on touch, and have a delayed capillary refill (> 3 seconds) in the case of ischemia (arterial compromised flap).

A lack of blood and oxygen to the tissue causes skin flap necrosis, which can appear anywhere from the second to the fourth day after surgery. On the leading edge of the flap, it often appears as a black patch or a blood-stained blister. Necrosis is a serious consequence that can necessitate additional surgical procedures, cause various infections, and cause treatment to be delayed. Severe ischemia, arising from obstructed artery input, causes necrosis, particularly in the flap's distal portion.

Glyceryl nitrate, commonly known as nitroglycerin, is an organic nitrate [3]. It's a direct topical vasodilator that comes in ointment, solution, and transdermal patch forms. It relaxes vascular smooth muscle by releasing nitric oxide, inducing intracellular cyclic guanosine monophosphate, and inhibiting myosin light chain kinase [1]. An increase in the calibre of arteries and veins increases blood flow to the application site [2]. Nitroglycerin, on the other hand, has no effect on the ratio of pre- to post-capillary resistance; net blood flow is high [4]. The microcirculation of the area is disrupted after flap elevation, resulting in the production of vasoactive cytokines and secondary thrombosis, eventually leading to ischemic necrosis of the flap [5]. Although it is known that sublingual 
nitroglycerin alters vasculogenesis [6]. it is unknown whether topical NTG has a similar effect in a flap.

In a study by Rachel et al [7]. in evaluating the efficacy of topical nitroglycerin application with a reduced Mastectomy skin flap necrosis, it was concluded that nitroglycerin increases the chance of flap survival and has an excellent safety profile. When comparing thrombolytics, anticoagulants, and vasodilators in rats, Aral et al. found that only anticoagulants significantly reduce skin flap necrosis [5]. Cui et al. showed that dietary nitrate supplementation altered the blood flow of ischemic skin flaps in rats [8].

In our study, we found that topical application of nitroglycerin is efficacious, increases the chances of flap survival, easy to use, and is cost-effective. No adverse effects after the application of nitroglycerin solution were noticed during the study. The limitation of our study is that, since this single case report study, definite conclusions cannot be made. This study can also be used as the basis for a larger prospective study to determine the efficacy of topical NTG in increasing the chances of flap survival and if nutritional interventions could optimize patients before surgery.

\section{Conclusion}

Nitroglycerin appeared to be an excellent agent for improving flap survival in skin flaps. It has a good safety profile and is thus appropriate for empirical use.

\section{Conflicts of interest: None}

Authors' contributions: All authors made contributions to the article

Availability of data and materials: Not applicable.

Financial support and sponsorship: None.

Consent for publication: Not applicable

\section{References}

1. Gdalevitch P, Laeken NV, Bahng S, et al. (2015) Effects of Nitroglycerin Ointment on Mastectomy Flap Necrosis in Immediate Breast Reconstruction: A Randomized Controlled Trial. Plast Reconstr Surg. 135(6): 15301539.

2. Rohrich RJ, Cherry GW, Spira M. (1984) Enhancement of skin flap survival using nitroglycerin ointment. Plast Reconstr Surg. 73(6): 943-948.

3. Yun MH, Yoon ES, Lee BI, Park SH. (2017) The effect of low-dose nitroglycerin ointment on skin flap necrosis in breast reconstruction after skin-sparing or nipplesparing mastectomy. Arch Plast Surg. 44(6): 509-515.

4. Scheuer S, Hanna MK. (1986) Effect of nitroglycerin ointment on penile skin flap survival in hypospadias repair Experimental and clinical studies. Urology. 27(5): 438-440.

5. Aral M, Tuncer S, Şencan A, Elmas Ç, Ayhan S. (2015) The Effect of Thrombolytic, Anticoagulant, and Vasodilator Agents on the Survival of Random Pattern Skin Flap. J Reconstr Microsurg. 31(7): 487-492.

6. Di Fabio JM, Thomas GR, Zucco L, et al. (2006) Nitroglycerin attenuates human endothelial progenitor cell differentiation, function, and survival. J Pharmacol Exp Ther. 318(1): 117-123.

7. Vania, Rachel, Pranata, Raymond, Irwansyah, et al. (2020) Topical Nitroglycerin is Associated with a Reduced Mastectomy Skin Flap Necrosis- Systematic Review and Meta-analysis. Journal of Plastic, Reconstructive \& Aesthetic Surgery. 73(6): 1050-1059.

8. Cui H, Wang Y, Feng Y, Li X. (2019) No Title. Biochem Biophys Res Commun. 515(1): 44-49. 